\title{
Aloe-Emodin Induces Chondrogenic Differentiation of ATDC5 Cells via MAP Kinases and BMP-2 Signaling Pathways
}

\author{
Ming Yang ${ }^{1}$, Liang $\mathrm{Li}^{2}$, Seok-Mo Heo ${ }^{1, *}$ and Yunjo Soh ${ }^{2, *}$ \\ ${ }^{1}$ Department of Periodontology, School of Dentistry, ${ }^{2}$ Department of Dental Pharmacology, School of Dentistry and Institute of Oral \\ Bioscience, Chonbuk National University, Jeonju 54896, Republic of Korea
}

\begin{abstract}
Endochondral bone formation is the process by which mesenchymal cells condense into chondrocytes, which are ultimately responsible for new bone formation. The processes of chondrogenic differentiation and hypertrophy are critical for bone formation and are therefore highly regulated. The present study was designed to investigate the effect of aloe-emodin on chondrogenic differentiation in clonal mouse chondrogenic ATDC5 cells. Aloe-emodin treatment stimulated the accumulation of cartilage nodules in a dose-dependent manner. ATDC5 cells were treated with aloe-emodin and stained with alcian blue. Compared with the control cells, the ATDC5 cells showed more intense alcian blue staining. This finding suggested that aloe-emodin induced the synthesis of matrix proteoglycans and increased the activity of alkaline phosphatase. Aloe-emodin also enhanced the expressions of chondrogenic marker genes such as collagen II, collagen X, BSP and RunX2 in a time-dependent manner. Furthermore, examination of the MAPK signaling pathway showed that aloe-emodin increased the activation of extracellular signal-regulated kinase (ERK), but had no effect on p38 and c-jun N-terminal kinase (JNK). Aloe-emodin also enhanced the protein expression of BMP-2 in a time-dependent manner. Thus, these results showed that aloe-emodin exhibited chodromodulating effects via the BMP-2 or ERK signaling pathway. Aloe-emodin may have potential future applications for the treatment of growth disorders.
\end{abstract}

Key Words: Aloe-emodin, ATDC5 cells, Chondrogenesis, MAP kinases, BMP-2

\section{INTRODUCTION}

Cartilage is a connective tissue that is comprised primarily of matrix (mainly collagens and proteoglycans) containing relatively sparse populations of chondrocytes, which perform matrix-generation and maintenance functions (Zuscik et al., 2008). Damaged cartilage has limited ability to repair itself. Therefore, focal or diffuse cartilage defects often require orthopedic surgery (Wakitani et al., 1998). Although the number of patients who need such treatment is significantly lower than those with arthritis, localized defects present a possible first step in the regeneration of the articular surface.

Mesenchymal stem cells (MSCs) are a group of cells with multiple differentiation potentials (Jiang et al., 2015). These multipotent cells can be differentiated into chondrocytes, osteoblasts and adipocytes. Due to the development of bone marrow-derived mesenchymal stem cells, MSCs are ideal cells for the treatment of diseases of the musculoskeletal sys- tem. Over the past ten years, these cells have been used for the construction of tissue engineered articular cartilage defects and have received great attention in terms of manipulability in vitro (Pittenger et al., 1999).

Natural anthraquinone derivatives are found in the root extracts, bark or leaves of many plants used primarily as laxatives. Over the last few decades, these compounds have been investigated as potential cancer treatments (Mueller et al., 1998; Huang et al., 2005; Kim et al., 2005; Mijatovic et al., 2005; Lin et al., 2006). Rhubarb (Rheum rhabarbarum) is a well-known traditional Chinese herbal medicine commonly used to treat constipation, jaundice, gastrointestinal hemorrhage, and ulcers (Hu et al., 2014). Anthraquinone derivatives, including emodin and aloe-emodin, are the main active ingredients found in rhubarb (Komatsu et al., 2006).Emodin reportedly have a variety of biology activities, such as antiinflammatory and anticancer. Emodin also induced osteoblast differentiation and increased the area of new bone formation

\section{Open Access http://dx.doi.org/10.4062/biomolther.2016.020}

This is an Open Access article distributed under the terms of the Creative Commons Attribution Non-Commercial License (http://creativecommons.org/licenses/by-nc/4.0/) which permits unrestricted non-commercial use, distribution, and reproduction in any medium, provided the original work is properly cited.
Received Jan 28, 2016 Revised Apr 28, 2016 Accepted May 24, 2016 Published Online Jul 1, 2016

\section{*Corresponding Authors}

E-mail: neoheo@jbnu.ac.kr (Heo SM), ysoh@jbnu.ac.kr (Soh Y) Tel: +82-63-250-2018 (Heo SM), +82-63-270-4038 (Soh Y) Fax: +82-63-250-2259 (Heo SM), +82-63-270-4037 (Soh Y) 
by inducing BMP-2 through activation of the MAP kinase-NF$\kappa \mathrm{B}$ signaling pathway in MC3T3-El cells (Kim et al., 2014). Aloe-emodin is a compound with anti-rheumatic, anti-inflammatory and analgesic properties (Nesslany et al., 2009). To our knowledge, this is the first to report the inducing effect of aloe-emodin on chondrogenic differentiation of ATDC5 Cells (Fig. 1).

In this study, we found that aloe-emodin had stimulatory effects on ATDC5 cells, leading to increased chondrogenesis. Furthermore, aloe-emodin induced matrix proteoglycan synthesis and the expression of chondrogenic marker genes such as type II collagen and bone sialoprotein (BSP), as well as chondrogenic signaling molecules, including runt-related transcription factor 2 (Runx2) and sex determining region Y-box 9 (Sox9). We suggest here that aloe-emodin can reduce the effect of various diseases associated with skeletal disorders.

\section{MATERIALS AND METHODS}

\section{Materials}

Aloe-emodin was purchased from Santa Cruz Biotechnology Inc. (Santa Cruz, CA, USA). Cell culture medium and fetal bovine serum (FBS) were obtained from Invitrogen (Gaithersburg, MD, USA). PCR primers were purchased from Bioneer (Daejcon, Korea). All other chemicals were purchased from Sigma (St. Louis, MO, USA), and unless otherwise indicated, were purchased as described in the previous paper by Choi<smiles>O=C1c2cccc(O)c2C(=O)c2c(O)cc(CO)cc21</smiles>

Fig. 1. Chemical structure of Aloe-emodin. et al. (2011). The resulting Intracellular purple formazan was quantified using a spectrophotometer to measure the absorbance at a wavelength of $540 \mathrm{~nm}$.

\section{Cell culture and differentiation}

Pre-chondrogenic ATDC5 cells were purchased from the RIKEN Cell Bank (Ibaraki, Japan). ATDC5 cells were cultured in a 1:1 mixture of Dulbecco's modified Eagle's medium (DMEM) and Hams' F-12 medium (Invitrogen), including 5\% FBS, penicillin $(100 \mathrm{U} / \mathrm{ml})$, and streptomycin $(100 \mu \mathrm{g} / \mathrm{ml})$. The cells were cultured in a humidified atmosphere of $5 \% \mathrm{CO}_{2}$ at $37^{\circ} \mathrm{C}$ for different time periods (up to 14 days). The original medium was replaced with a differentiation medium containing $10 \mu \mathrm{g} / \mathrm{ml}$ transferrin, $3 \times 10^{-8} \mathrm{M}$ sodium selenite, $10 \mu \mathrm{g} / \mathrm{ml}$ bovine insulin. In the present study, we used aloe-emodin instead of bovine inulin to induce chondrogenic differentiation of the ATDC5 cells, and the culture medium was replaced every two days.

\section{MTT assay}

ATDC5 cells $\left(5 \times 10^{3}\right.$ cells) were seeded in a 96-well palte with medium and incubated for $24 \mathrm{~h}$ with $10 \%$ FBS. After the initial incubation period, the cells were treated with varying concentrations of aloe-emodin. Next, the cells were washed with phosphate-buffered saline (PBS) and treated with media containing $100 \mu \mathrm{g} / \mathrm{ml}$ MTT [3-(4, 5-dimethylthiazol-2-yl)-2, 5-diphenyltetrazolium bromide] for $2 \mathrm{~h}$ at $37^{\circ} \mathrm{C}$. The cells were then washed with PBS, and dissolved in $200 \mu$ of DMSO. For the resulting solubilized purple formazan, a quantitative determination of the absorption at $540 \mathrm{~nm}$ was carried out using a spectrophotometer.

\section{Alcian blue staining}

ATDC5 cells were cultured for 21 days. Cells were washed twice with PBS, and fixed with methanol at $-20^{\circ} \mathrm{C}$ for 5 minutes. They were then stained with $0.1 \%$ Alcian blue $8 \mathrm{GX}$ in $0.1 \mathrm{M} \mathrm{HCL}$ overnight. Cells were washed with $3 \%$ acetic acid

Table 1. Primer sequences and conditions for RT-PCR

\begin{tabular}{|c|c|c|c|c|}
\hline \multirow{2}{*}{ Target genes (Accession number) } & \multirow{2}{*}{ Primers Forward/Reverse } & \multicolumn{3}{|c|}{ PCR condition } \\
\hline & & $\operatorname{Tm}\left({ }^{\circ} \mathrm{C}\right)$ & Cycles & Size (bp) \\
\hline \multirow[t]{2}{*}{ Collagen II (NM_031163) } & 5'-ctgtaagaacagcatcgcctacctg-3' & 60 & 27 & 271 \\
\hline & 5'-caggaatttggtgtggacataggg-3' & & & \\
\hline \multirow[t]{2}{*}{ Aggrecan (NM_007424) } & 5'-catgagagaggccaatggaacg-3' & 55 & 27 & 257 \\
\hline & 5'-gaatcacctgcacagacccaa-3' & & & \\
\hline \multirow[t]{2}{*}{ Collagen I (NM_007742) } & 5'-ttctcctggtaaagatggtgc-3' & 50 & 35 & 254 \\
\hline & 5'-tgttaaaggtgatgctggtcc-3' & & & \\
\hline \multirow[t]{2}{*}{ Collagen X (NM_009925) } & 5'-cgtctctgcttttactgtca-3' & 48 & 35 & 300 \\
\hline & 5'-ctcacagaaaatgaccaggt-3' & & & \\
\hline \multirow[t]{2}{*}{ Runx2 (NM_009820) } & 5'-actttctccaggaagactgc-3' & 50 & 37 & 366 \\
\hline & 5'-acagcaacagcaacaacagc-3' & & & \\
\hline \multirow[t]{2}{*}{ Osterix (AF184902) } & 5'-actacccacccttccctcac-3' & 55 & 33 & 360 \\
\hline & 5'-ccttaacccagctccctacc-3' & & & \\
\hline \multirow[t]{2}{*}{ BSP (NM_008318) } & 5'-gagccaggactgccgaaaggaa-3' & 60 & 29 & 653 \\
\hline & 5'-gcagcagcggaggagaaacgg-3' & & & \\
\hline \multirow[t]{2}{*}{ GAPDH (NM_008084) } & 5'-accacagtccatgccatcac-3' & 56 & 25 & 452 \\
\hline & 5'-tacagcaacagggtggtgga-5" & & & \\
\hline
\end{tabular}


A

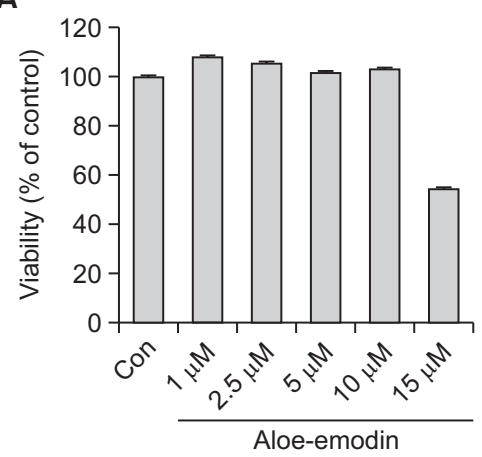

B

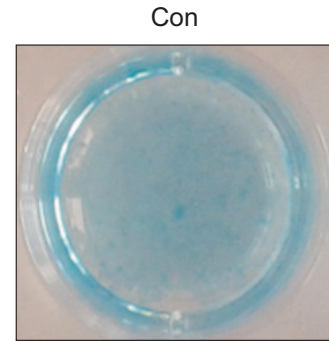

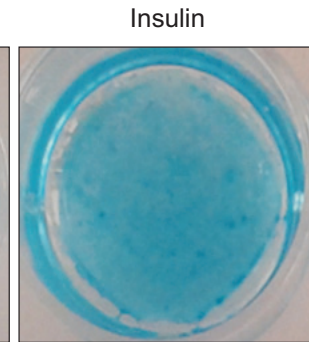

C
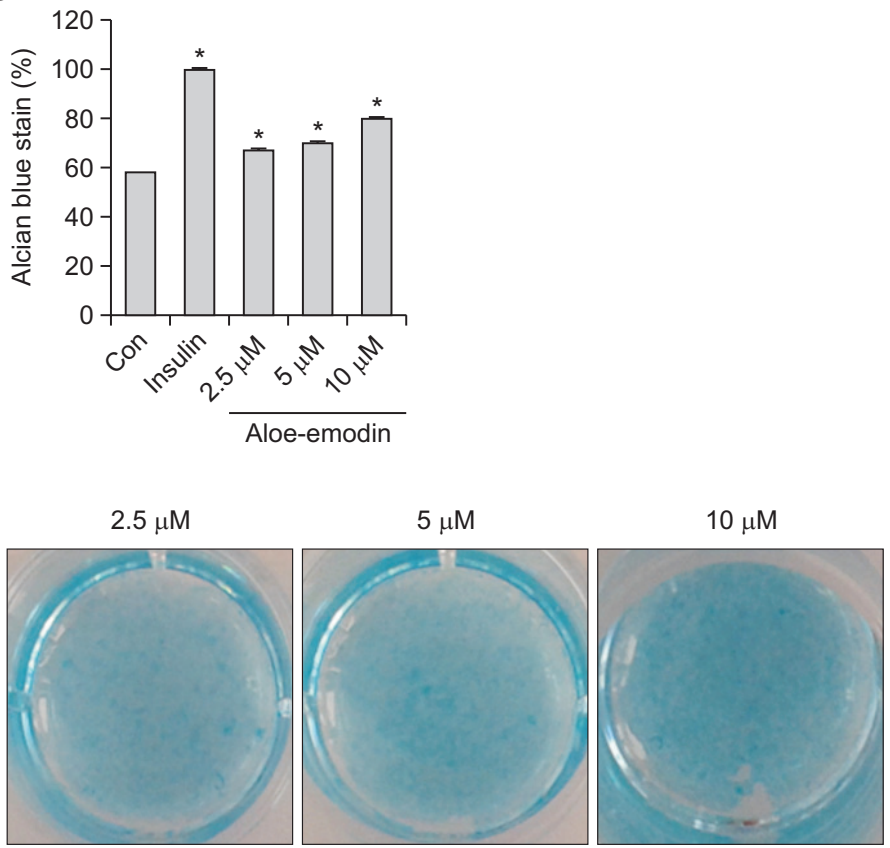

Fig. 2. Effects of aloe-emodin on proliferation and differentiation of ATDC5 cells. ATDC5 cells were treated with indicated concentrations of aloe-emodin for 3 days and cell viability was measured by an MTT assay (A). Cells were incubated with aloe-emodin $(2.5 \mu \mathrm{M}, 5 \mu \mathrm{M}, 10 \mu \mathrm{M})$ and $10 \mu \mathrm{g} / \mathrm{ml}$ insulin, and plated with $\left(5 \times 10^{4}\right)$ cells per well with 24 -multiwell plates for 14 days. Stained cells were dissolved in $10 \%$ acetic acid for quantification of the absorbance at $650 \mathrm{~nm}(\mathrm{~B})$. The normalized data was shown in (C) where the asterisk $\left(^{*}\right)$ indicates a significant difference $(p<0.05)$ compared to the control. Each histogram represents the mean $\pm S E(n=3)$.

three times for $30 \mathrm{~s}$ and then photographed. Stained cells were dissolved in $10 \%$ acetic acid for subsequent quantification of the absorbance at $650 \mathrm{~nm}$ (Shukunami et al., 1997).

\section{Reverse transcription-polymerase chain reaction (RT-PCR)}

Total RNA was isolated from the ATDC5 cells using a TRIZOL reagent (Invitrogen). cDNA was synthesized from 4 $\mu \mathrm{g}$ of total RNA using SuperScript II reverse transcriptase (Invitrogen) according to the manufacturer's instructions. PCR primers were purchased from Bioneer (Daejeon, Korea). The gene-specific primers used for the PCR reactions, primer sequences and conditions are listed in Table 1. The reaction was initiated at $95^{\circ} \mathrm{C}$ for 1 minute. Amplification was performed for various cycles. Every cycle consisted of denaturation for 30 $\mathrm{s}$ at $94^{\circ} \mathrm{C}$, annealing for 1 minute at the primer-pair specific temperature, and extension for 2 minutes at $72^{\circ} \mathrm{C}$ using Taq polymerase (Promega, Madison, WI, USA). Reaction products $(10 \mu \mathrm{l})$ were separated on a $0.8 \%$ agarose gel stained with ethidium bromide, and analyzed densitometrically. Band intensity was analyzed by densitometry using a phosphoimager and Quantity One version 4.3.1 software (Bio-Rad, Hercules, CA, USA).

\section{Alkaline phosphatase (ALP) activity}

Cells were harvested and homogenized in a lysis buffer (50 mM Tris pH 7.4, $150 \mathrm{mM} \mathrm{NaCl}, 1 \mathrm{mM}$ EDTA). The lysed suspension was then centrifuged at $13,200 \times \mathrm{g}$ for $15 \mathrm{~min}$ and the supernatant was collected. The cellular protein concentration was evaluated by a Bradford assay. ALP activity was measured by a spectrophotometer with para-nitrophenylphosphate (Sigma) as the substrate. Optical density was measured at $405 \mathrm{~nm}$ using an enzyme-linked immunosorbent assay (ELISA) reader.

\section{Western blot analysis}

Following treatment, ATDC5 cells were washed with icecold phosphate-buffered saline (PBS) and lysed in an ice-cold lysis buffer (50 mM Tris- $\mathrm{HCl}, 150 \mathrm{mM} \mathrm{NaCl}, 1 \% \mathrm{NP} 40,0.25 \%$ sodium deoxycholate, $1 \mathrm{mM}$ EDTA, $1 \mathrm{mM} \mathrm{Na}_{3} \mathrm{VO}_{4}, 1 \mathrm{mM}$ phenylmethylsulfonyl fluoride (PMSF), $1 \mu \mathrm{g} / \mathrm{ml}$ leupeptin, 1 $\mu \mathrm{g} / \mathrm{ml}$ pepstatin, $5 \mu \mathrm{g} / \mathrm{ml}$ aprotinin, and $20 \mathrm{mM} \mathrm{NaF}$ ), and kept on ice for 40 minutes. Cell lysates were centrifuged at 13,200 $\mathrm{g}$ at $4^{\circ} \mathrm{C}$ for 10 minutes and the supernatants were stored at $-80^{\circ} \mathrm{C}$ for analysis. The proteins were electrophoresed by $10 \%$ SDS-PAGE and then transferred to a polyvinylidene difluoride (PVDF) membrane. Next, a 5\% nonfat milk in Tris-buffered saline (TBS) containing $0.25 \%$ Tween-20 (TTBS) was used to block the membranes at $16^{\circ} \mathrm{C}$ for $1 \mathrm{~h}$. The rabbit anti-phospho ERK (Cell Signaling Technology Inc., Beverly, MA, USA), anti-phospho p38 (Cell Signaling Technology), anti-phospho JNK (Cell signaling Technology), anti-ERK (Cell Signaling Technology), anti-JNK (Cell signaling Technology), anti-p38 (Cell Signaling Technology), anti-BMP-2 (Abcam, Cambridge, MA, USA), and anti-ALP (Santa Cruz Biotechnology) antibodies were diluted to $1: 500-1: 1,000$ in $5 \%$ nonfat milk in TTBS. Secondary antibodies were diluted with 1:5000-1:10,000 in $5 \%$ nonfat skim in TTBS for $1 \mathrm{~h}$ at room temperature. Blots were developed with an ECL western blot detection reagent (Amersham Biosciences, Piscataway, NJ, USA) and exposed to X-ray film. 
A
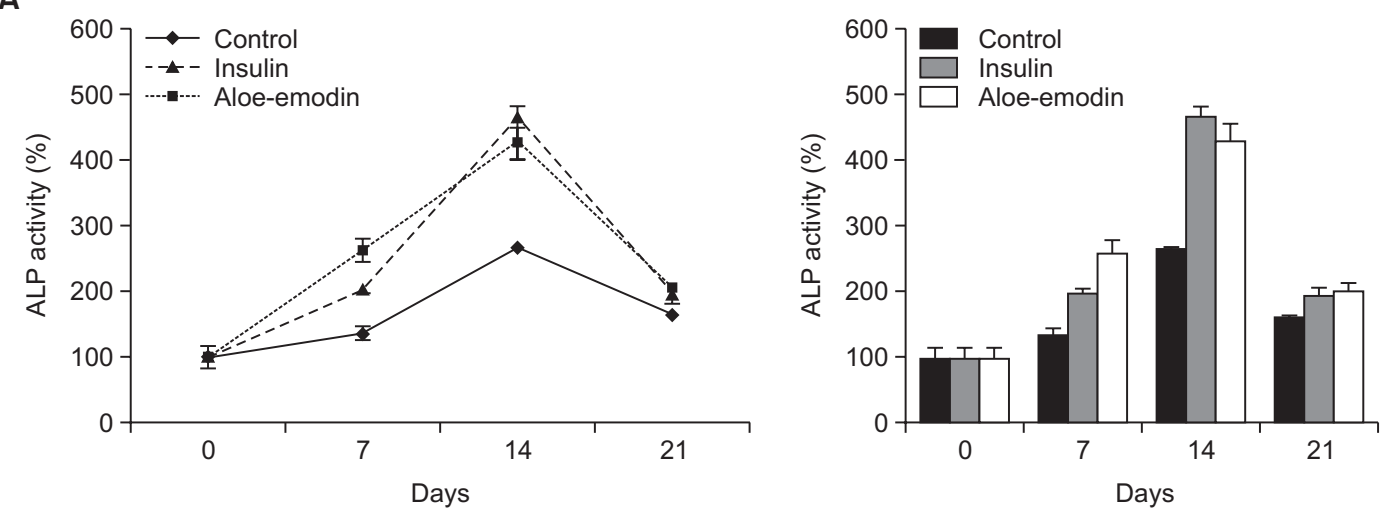

B
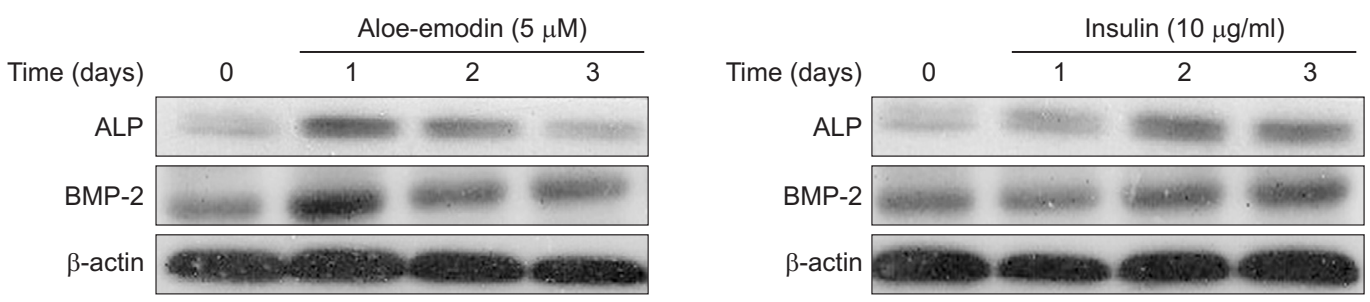

Fig. 3. Effect of aloe-emodin on alkaline phosphatase activity, BMP-2 and ALP in ATDC5 cells. ATDC5 cells were treated with $10 \mu M$ aloeemodin and $10 \mu \mathrm{g} / \mathrm{ml}$ insulin for 21 days, the level of alkaline phosphatase activity (\%) compared with control and insulin-treated cells (A). The ATDC5 cells were treated with $5 \mu \mathrm{M}$ aloe-emodin and $10 \mu \mathrm{g} / \mathrm{ml}$ insulin for $1,2,3$ days and cells lysates were immunoblotted with antibody against ALP and BMP-2 (B). Each gaph represents the mean \pm S.E.M. $(n=3)$.

\section{Statistical analysis}

The experiments were repeated at least three times, and all data were summarized as the mean \pm SEM. All statistical analyses were performed using the SPSS ver. 13.0 software. Statistical significance was set at $p$ less than 0.05 .

\section{RESULTS}

\section{Effect of aloe-emodin on proliferation and differentiation of ATDC5 cells}

Light microscopy was used to measure the in vitro effect of aloe-emodin on matrix proteoglycan formation as well as ATDC 5 cell proliferation and differentiation. Cells were treated with aloe-emodin at different concentrations $(1 \mu \mathrm{M}, 2.5 \mu \mathrm{M}, 5$ $\mu \mathrm{M}, 10 \mu \mathrm{M}$ and $15 \mu \mathrm{M})$ for $72 \mathrm{~h}$ and assessed with the MTT assay. Aloe-emodin at $1 \mu \mathrm{M}, 2.5 \mu \mathrm{M}, 5 \mu \mathrm{M}, 10 \mu \mathrm{M}$ concentrations exhibited no cytotoxic effects on ATDC5 compared to the control cells. However, aloe-emodin at $15 \mu$ Mconcentration showed high toxicity (Fig. 2A).

We used alcian blue staining to verify the production of matrix proteoglycan after treatment for 14 days with aloe-emodin in ATDC5 cells (Fig. 2B, 2C). Compared with the control cells, the size and number of stained nodules were significantly increased by aloe-emodin in a concentration-dependent manner in ATDC5 cells. These results suggest that aloe-emodin can induce the differentiation of ATDC5 cells.

\section{Effects of aloe-emodin on alkaline phosphatase activity, BMP-2 and ALP in ATDC5 cells}

The enzymatic activity of alkaline phosphatase (ALP) was determined in cells treated with $10 \mu \mathrm{M}$ aloe-emodin and com- pared to cells treated with insulin. ALP activity was significantly increased in cells treated with $10 \mu \mathrm{M}$ aloe-emodin compared to the control cells. ALP activity was also increased in cells treated with $10 \mu \mathrm{g} / \mathrm{ml}$ insulin compared to control cells after 14 days (Fig. 3A). To determine the role of aloe-emodin activation of chondrogenesis in ATDC5 cells via BMP-2 and ALP signaling pathways, we treated ATDC5 cells with aloe-emodin in a time-dependent manner. Treatment with $5 \mu \mathrm{M}$ aloe-emodin significantly increased the expression of BMP-2 at day 1, and insulin increased the expression of BMP-2 at day 2. Furthermore, the expression of ALP was also significantly increased by $5 \mu \mathrm{M}$ aloe-emodin after $24 \mathrm{~h}$ and insulin increased the expression of ALP after $48 \mathrm{~h}$ (Fig. 3B).

\section{Expression of chondrogenic marker genes in ATDC5 cells treated with aloe-emodin}

Aloe-emodin significantly increased the expression of chondrogenic marker genes such as Aggrecan, bone sialoprotein (BSP) and Runx2 (Fig. 4A). To determine the stimulatory effect of aloe-emodin on chondrogenesis, the expressions of type II collagen, Aggrecan, type I collagen, type X collagen, Runx2, BSP, and Osterix were measured using real-time PCR (Fig. 4B). ATDC5 cells were treated with $5 \mu \mathrm{M}$ aloe-emodin at different time intervals. The expressions of type II collagen, Aggrecan,type I collagen, and Osterix were significantly increased at 14 days. Similarly, type X collagen and Runx2 were also increased at 14 days and still in the stable state observation at 21 days. The expression pattern was similar to that of insulin, which was used as a positive control. In addition, BSP had significant expression at 21 days. These results suggest that aloe-emodin induces chondrogenic differentiation in ATDC5 cells. 
A

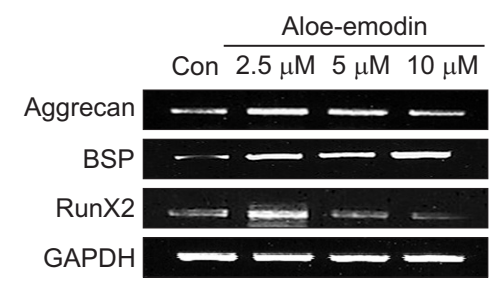

B

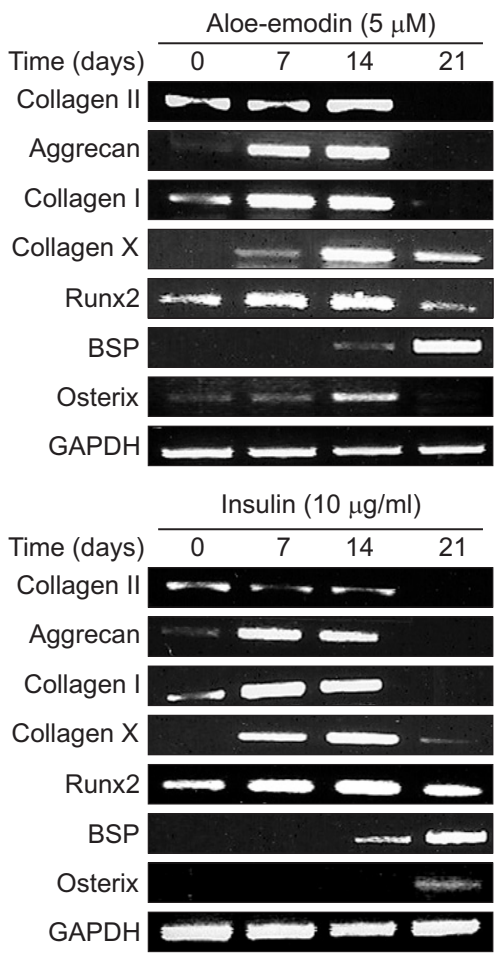

Fig. 4. Expression of chondrogenic marker genes in ATDC 5 cells treated with aloe-emodin. ATDC5 cells were treated with $2.5 \mu \mathrm{M}$, $5 \mu \mathrm{M}, 10 \mu \mathrm{M}$ aloe-emodin for 21 days. The mRNA levels of different chondrogenic marker molecules, including Aggrecan, BSP and Runx2 were determined by RT-PCR analysis and compared to the levels of GAPDH (A). ATDC5 cells were treated with $5 \mu \mathrm{M}$ aloe-emodin or $10 \mu \mathrm{g} / \mathrm{ml}$ insulin were incubated for the indicated time periods (B). Relative expression of type II collagen, Aggrecan, type I collagen, type $X$ collagen, Runx2, BSP and Osterix were observed by RT-PCR analysis and compared to GAPDH.

\section{Effect of aloe-emodin on MAP kinase activation in ATDC5 cells}

Next, we investigated whether aloe-emodin had any effects on mitogen-activated protein kinase (MAPKs) or not. MAPK is involved in signal transduction networks and contributes to a diverse range of cellular events, including cell differentiation (Bobick et al., 2007), proliferation (Longobardi et al., 2006), migration (Kuang et al., 2008) and apoptosis (Junttila et al., 2008). Insulin was used as a positive control, and aloe-emodin was used for comparison of the phosphorylation of ERK, JNK and p38. When cells were treated with $10 \mu \mathrm{M}$ aloe-emodin, the p-ERK significantly increased at $0.5 \mathrm{~h}$, similar to the insulin group. (Fig. 5). This result suggests that aloe-emodin can modulate the differentiation of ATDC5 cells via the ERK signaling pathway.
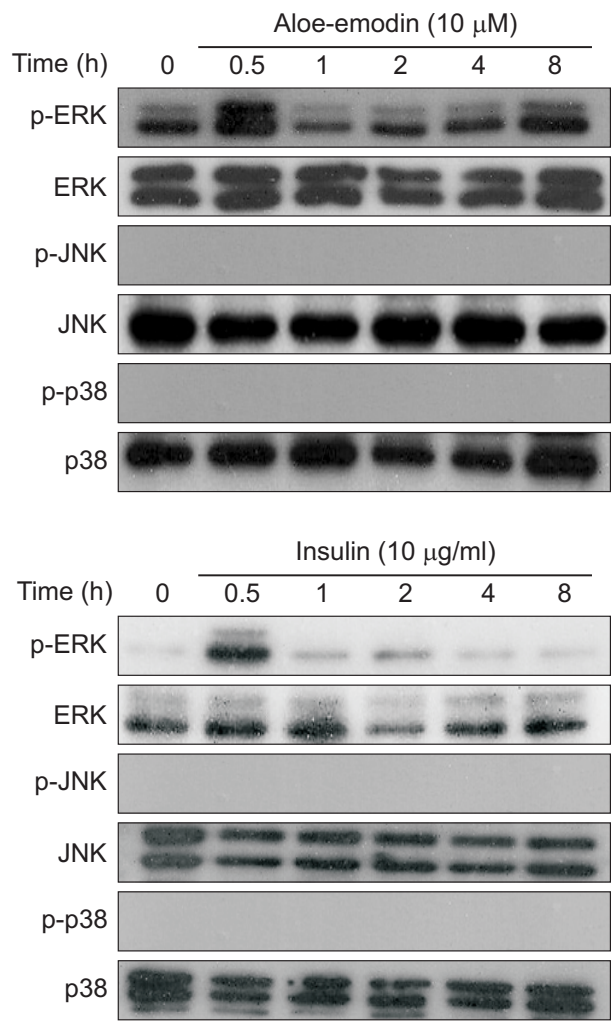

Fig. 5. Effect of aloe-emodin on MAP kinase activation in ATDC5 cells. Cells were cultured in a serum free media for $16 \mathrm{~h}$, and then treated with $10 \mu \mathrm{M}$ aloe-emodin or $10 \mu \mathrm{g} / \mathrm{ml}$ insulin for indicated times. The cells extracts were using specific antibodies against the phosphorylated forms of the MAPKs and analyzed by Western blot. These data were compared to data obtained with antibodies directed against the unphosphorylated states of the kinase.

\section{Effect of MAP kinase inhibitor on chondrogenesis with aloe-emodin in ATDC5 cells}

To demonstrate the effect of aloe-emodin on the induction of ERK during ATDC5 cell differentiation, cells were pretreated cells with $20 \mu \mathrm{M}$ PD 98059 for 30 minutes, followed by treatment with aloe-emodin for 14 days. Alcian blue staining demonstrated that cells treated with aloe-emodin showed significant increases in the size and number of nodules while treatment with PD 98059 significantly inhibited the increase (Fig. 6). The data suggested that aloe-emodin can induce ATDC5 cells differentiation via the ERK signaling pathway.

\section{DISCUSSION}

Chondrogenesis is an important biological process involved in tissue patterning bone development, and endochondral ossification. Chondrogensis begins with the formation of multipotent mesenchymal cells which proliferate and differentiate into chondrocytes (Kronenberg, 2003). Chondrocyte cellular biosynthetic activities of optimal maintenance histories led to the development of cartilage matrix concentration and structural organization (Mauck et al., 2006). However, there are many factors that can influence longitudinal bone growth (Pass et al., 2009). Nutritional, hormonal, and mechanical factors all have effects on cell proliferation, hypertrophy, death, and bone 
A

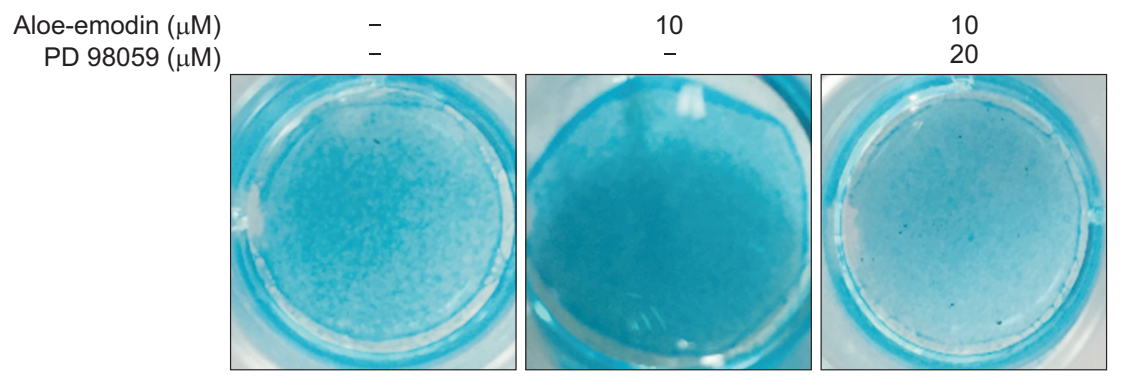

B

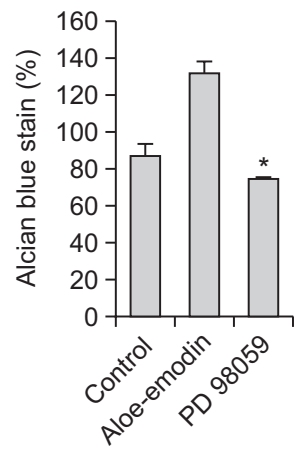

Fig. 6. Effect of MAP kinase inhibitor on chondrogenesis with aloe-emodin in ATDC5 cells. ATDC5 cells were treated with aloe-emodin and seeded at a density of $\left(5 \times 10^{4}\right)$ cells per well for 14 days in the presence or absence of $20 \mu \mathrm{M}$ PD 98059 (A). Stained cells were dissolved in $10 \%$ acetic acid for subsequent quantification of the absorbance at $650 \mathrm{~nm}(B)$. Each histogram represents the mean $\pm S$.E.M. $(n=3)$.

formation.

Chondrogenic differentiation molecular mechanisms during in vitro endochondral bone formation has been used by chondrocytes or established chondrogenic cell lines. The mouse embryonal carcinoma-derived cell line ATDC5 cells are a good model of both in vitro endochondral bone growth control and of differentiation of chondroprogenitor cells. Previous studies have described the method in detail the ATDC5 differentiation and mineralization (Shukunami et al., 1997). This method has provided a reliable source of chondrocyte mineralization for several years and has been widely used in the field since its publication. These cells experience a similar growth plate, which is fully differentiated into hypertrophic chondrocytes in the presence of insulin (Snelling et al., 2010). ATDC5 cells retain the properties of chondroprogenitor cells, and rapidly proliferate in the presence of 5\% FBS. Insulin (10 micrograms/ $\mathrm{ml}$ ) induced chondrogenic differentiation of the cells in a postconfluent phase through a cellular condensation process, resulting in the formation of cartilage nodules (Shukunami et al., 1997). In our study, ATDC5 cells produced more cartilaginous nodules than the control cells. Alcian blue staining of the ATDC5 cells was more intense, suggesting greater synthesis of matrix proteoglycans. Aloe-emodin treated cells exhibited increased ALP activity. Moreover, the expressions of chondrogenic marker genes, such as type I collagen, type II collagen, type $\mathrm{X}$ collagen, bone sialoproten and Runx2, were induced by aloe-emodin treatment.

Interaction of the MAPK pathway and extracellular signals (e.g., stress induced cytokines, growth factors, and hormones) results in a variety of physiological responses including cell proliferation, differentiation and apoptosis (Roberts and Der, 2007). MAPK and BMP signaling pathways both contribute to chondrogenic signaling. The MAPK pathway, including ERK and $\mathrm{p} 38$, plays a key role in many types of cell differentiation signaling processes (Oh et al., 2000). In addition, JNK is known to control cell proliferation, differentiation, and apoptosis (Davis, 2000). In the present study, we showed that treating ATDC5 cells with aloe-emodin results in the activation of ERK. BMP-2 belongs to the transforming growth factor beta (TGF- $\beta$ ) super-family. BMPsare initially determined byinducing the ectopic bone and cartilage formation of its unique ability (Otsuki et al., 2010). However, it also play an important role in the ear- liest stages of chondrogenesis. BMP-2 induces chondrogenic differentiation and chondrocyte proliferation (Yoon and Lyons, 2004), and markedly up-regulates the expression of type $X$ collagen mRNA in late-phase differentiation (Akiyama et al., 2000). BMP-2 also stimulates RunX expression and ALP, a widely accepted bone marker (Kim et al., 2004). BMP-2 can be detected in the health articular cartilage, but it is highly expressed in osteoarthritis articular cartilage and subjected to mechanical damage of articular chondrocytes and synovial cells, possibly cause anabolic cartilage cells formation and development of osteophyte (van Beuningen et al., 1988; Nakase et al., 2003). In our study, aloe-emodin significantly increased the expression of BMP-2 in ATDC5 cells, suggesting that aloe-emodin may activate chondrogenesis through the BMP-2 signaling pathway in addition to the ERK and ALP signaling pathways.

\section{ACKNOWLEDGMENTS}

This research was supported by Basic Science Research Program through the National Research Foundation of Korea (NRF) funded by the Ministry of Science, ICT \& Future Planning (NRF-2014R1A1A2A16055076).

\section{REFERENCES}

Akiyama, H., Shukunami, C., Nakamura, T. and Hiraki, Y. (2000) Differential expressions of BMP family genes during chondrogenic differentiation of mouse ATDC5 cells. Cell Struct. Funct. 25, 195-204.

Bobick, B. E., Thornhill, T. M. and Kulyk, W. M. (2007) Fibroblast growth factors 2, 4, and 8 exert both negative and positive effects on limb, frontonasal, and mandibular chondrogenesis via MEKERK activation. J. Cell Physiol. 211, 233-243.

Choi, H. J., Nepal, M., Park, Y. R., Lee, H. K., Oh, S. R. and Soh, Y. (2011) Stimulation of chondrogenesis in ATDC5 chondroprogenitor cells and hypertrophy in mouse by Genkwadaphnin. Eur. J. Pharmacol. 655, 9-15.

Davis, R. J. (2000) Signal transduction by the JNK group of MAP kinases. Cell 103, 239-252.

Huang, Q., Shen, H. M. and Ong, C. N. (2005) Emodin inhibits tumor cell migration through suppression of the phosphatidylinositol 3-kinase-Cdc42/Rac1 pathway. Cell. Mol. Life Sci. 62, 1167-1175. 
Hu, B. Y., Zhang, H., Meng, X. L., Wang, F. and Wang, P. (2014) Aloeemodin from rhubarb (Rheum rhabarbarum) inhibits lipopolysaccharide-induced inflammatory responses in RAW264.7 macrophages. J. Ethnopharmacol. 153, 846-853.

Jiang, C., Ma, P., Ma, B., Wu, Z., Qiu, G., Su, X., Xia, Z., Ye, Z. and Wang, Y. (2015) Plasma-derived fibronectin stimulates chondrogenic differentiation of human subchondral cortico-spongious progenitor cells in late-stage osteoarthritis. Int. J. Mol. Sci. 16, 1947719489.

Junttila, M. R., Li, S. P. and Westermarck, J. (2008) Phosphatase-mediated crosstalk between MAPK signaling pathways in the regulation of cell survival. FASEB J. 22, 954-965.

Komatsu, K., Nagayama, Y., Tanaka, K., Ling, Y., Basnet, P. and Meselhy, M. R. (2006) Development of a high performance liquid chromatographic method for systematic quantitative analysis of chemical constituents in rhubarb. Chem. Pharm. Bull. 54, 941-947.

Kim, J. Y., Cheon, Y. H., Kwak, S. C., Baek, J. M., Yoon, K. H., Lee, M. S. and Oh, J. (2014) Emodin regulates bone remodeling by inhibiting osteoclastogenesis and stimulating osteoblast formation. J. Bone Miner. Res. 29, 1541-1553.

Kim, M. S., Park, M. J., Kim, S. J., Lee, C. H., Yoo, H., Shin, S. H., Song, E. S. and Lee, S. H. (2005) Emodin suppresses hyaluronic acid-induced MMP-9 secretion and invasion of glioma cells. Int. J. Oncol. 27, 839-846.

Kim, Y. J., Lee, M. H., Wozney, J. M., Cho, J. Y. and Ryoo, H. M. (2004) Bone morphogenetic protein-2-induced alkaline phosphatase expression is stimulated by DIx5 and repressed by Msx2. J. Biol. Chem. 279. 50773-50780.

Kronenberg, H. M. (2003). Developmental regulation of the growth plate. Nature 423, 332-336.

Kuang, D., Zhao, X., Xiao, G., Ni, J., Feng, Y., Wu, R. and Wang, G. (2008) Stem cell factor/c-kit signaling mediated cardiac stem cell migration via activation of p38 MAPK. Basic Res. Cardiol. 103 265-273.

Lin, J. G., Chen, G. W., Li, T. M., Chouh, S. T., Tan, T. W. and Chung J. G. (2006) Aloe-emodin induces apoptosis in T24 human bladder cancer cells through the p53 dependent apoptotic pathway. J. Urol. 175, 343-347.

Longobardi, L., O'Rear, L., Aakula, S., Johnstone, B., Shimer, K., Chytil, A., Horton, W. A., Moses, H. L. and Spagnoli, A. (2006) Effect of IGF-I in the chondrogenesis of bone marrow mesenchymal stem cells in the presence or absence of TGF-beta signaling. J. Bone Miner. Res. 21, 626-636.

Mauck, R.L., Yuan, X. and Tuan, R. S. (2006) Chondrogenic differentiation and functional maturation of bovine mesenchymal stem cells in long-term agarose culture. Osteoarthr. Cartil. 14, 179-189.

Mijatovic, S., Maksimovic-Ivanic, D., Radovic, J., Miljkovic, D., Kaludjerovic, G. N., Sabo, T. J. and Trajkovic, V. (2005) Aloe-emodin decreases the ERK-dependent anticancer activity of cisplatin. Cell. Mol. Life Sci. 62, 1275-1282.
Mueller, S. O., Stopper, H. and Dekant, W. (1998) Biotransformation of the anthraquinones emodin and chrysophanol by cytochrome P450 enzymes. Bioactivation to genotoxic metabolites. Drug Metab. Dispos. 26, 540-546.

Nakase, T., Miyaji, T., Tomita, T., Kaneko, M., Kuriyama, K., Myoui, A., Sugamoto, K., Ochi, T. and Yoshikawa, H. (2003) Localization of bone morphogenetic protein-2 in human osteoarthritic cartilage and osteophyte. Osteoarthr. Cartil. 11, 278-284.

Nesslany, F., Simar-Meintières, S., Ficheux, H. and Marzin, D. (2009) Aloe-emodin-induced DNA fragmentation in the mouse in vivo comet assay. Mutat. Res. 678, 13-19.

Oh, C. D., Chang, S. H., Yoon, Y. M., Lee, S. J., Lee, Y. S., Kang, S. S. and Chun, J. S. (2000) Opposing role of mitogen-activated protein kinase subtypes, Erk-1/2 and p38, in the regulation of chondrogenesis of mesenchymes. J. Biol. Chem. 275, 5613-5619.

Otsuki, S., Hanson, S. R., Miyaki, S., Grogan, S. P., Kinoshita, M., Asahara, H., Wong C. H. and Lotz, M. K. (2010) Extracellular sulfatases support cartilage homeostasis by regulating BMP and FGF signaling pathways. Proc. Natl. Acad. Sci. U.S.A. 107, 10202-10207.

Pass, C., MacRae, V. E., Ahmed, S. F. and Farquharson, C. (2009) Inflammatory cytokines and the GH/IGF-I axis: novel actions on bone growth. Cell Biochem. Funct. 27, 119-127.

Pittenger, M. F., Mackay, A. M., Beck, S. C., Jaiswal, R. K., Douglas, R., Mosca, J. D., Moorman, M. A., Simonetti, D. W., Craig, S. and Marshak, D. R. (1999) Multilineage potential of adult human mesenchymal stem cells. Science 284, 143-147.

Roberts, P. J. and Der, C. J. (2007) Targeting the Raf-MEK-ERK mitogen-activated protein kinase cascade for the treatment of cancer. Oncogene 26, 3291-3310.

Shukunami, C., Ishizeki, K., Atsumi, T., Ohta, Y., Suzuki, F. and Hiraki, Y. (1997) Cellular hypertrophy and calcification of embryonal carcinoma-derived chondrogenic cell line ATDC5 in vitro. J. Bone Miner. Res. 12, 1174-1188.

Snelling, S. J., Hulley, P. A. and Loughlin, J. (2010) BMP5 activates multiple signaling pathways and promotes chondrogenic differentiation in the ATDC5 growth plate model. Growth Factors 28, 268279.

van Beuningen, H. M., Glansbeek, H. L., van der Kraan, P. M. and van den Berg, W. B. (1988) Differential effects of local application of BMP-2 or TGF- $\beta 1$ on both articular cartilage composition and osteophyte formation. Osteoarthr. Cartil. 6, 306-317.

Wakitani, S., Goto, T., Young, R. G., Mansour, J. M., Goldberg, V. M. and Caplan, A. I. (1998) Repair of large full-thickness articular cartilage defects with allograft articular chondrocytes embedded in a collagen gel. Tissue Eng. 4, 429-444.

Yoon, B. S. and Lyons, K. M. (2004) Multiple functions of BMPs in chondrogenesis. J. Cell. Biochem. 93, 93-103.

Zuscik, M. J., Hilton, M. J., Zhang, X. P., Chen, D. and O'Keefe, R. J. (2008) Regulation of chondrogenesis and chondrocyte differentiation by stress. J. Clin. Invest. 118, 429-438. 